\title{
SIMFONIČNI REPERTOAR GORIŠKE DEŽELE V 18. IN ZGODNJEM 19. STOLETJU
}

\author{
VESNA VENIŠNIK \\ Filozofska fakulteta Univerze v Ljubljani
}

Izvleček: Zgodovinski arhiv v Gorici (Archivio storico provinciale di Gorizia) hrani obsežno zbirko muzikalij iz 18. in začetka 19. stoletja. Zbirka je žanrsko raznolika, saj vsebuje cerkvena dela, solistična dela za instrumente s tipkami, zbirke arij, komorna dela in tudi precej simfoničnih del. Med zbirkami, relevantnimi za slovensko glasbeno zgodovino, je poleg arhiva ljubljanske Filharmonične goriška zbirka edina, ki dokazuje kontinuirano gojenje simfonične glasbe. Zbirka hrani dela različnih skladateljev: od $G$. C. Wagenseila, J. Stamitza in drugih Mannheimskih skladateljev preko A. Brioschija do zrelejših del J. Haydna, dela A. Gyrowetza in I. Pleyela ter njunih sodobnikov ter prvo in tretjo simfonijo L. Beethovna.

Ključne besede: simfonija, uvertura, instrumentalna glasba 18. in zgodnjega 19. stoletja, Zgodovinski arhiv v Gorici

\begin{abstract}
The Historical Archive of Gorizia holds a large collection of music from the eighteenth and early nineteenth centuries. It contains a variety of genres, including church, chamber, keyboard pieces, arias, and a large number of symphonic works. Among the collections relevant to Slovene music history this is the only one, apart from that of the Philharmonic Society of Ljubljana, that demonstrates a continuous cultivation of symphonic music. The collection includes a large array of works by different composers: from Georg Christoph Wagenseil, Johann Stamitz, and other Mannheim composers to Italian composers such as Antonio Brioschi, to mature works by Joseph Haydn and works by Adalbert Gyrowetz, Ignaz Pleyel and their contemporaries. There are also Beethoven's first and third symphonies.
\end{abstract}

Keywords: symphony, overture, instrumental music of the eighteenth and early nineteenth century, Historical Archive of Gorizia

Zgodovinski arhiv v Gorici hrani obsežno zbirko muzikalij iz 18. in začetka 19. stoletja. Zbirka vsebuje cerkvena dela, solistične skladbe za instrumente s tipkami, zbirke arij, komorna dela in številna simfonična dela. ${ }^{1}$ Najstarejša skladba iz zbirke, zanimiva za to raziskavo, je uvertura k operi Arsilda, regina di Ponto Antonija Vivaldija iz leta 1716. Gre za tipično italijansko operno sinfonio s trostavčno shemo hitro-počasi-hitro. ${ }^{2}$ Zaradi sorodnosti operne sinfonie $\mathrm{z}$ godalnimi skladbami tipa concerto da camera Corellijeve

1 Katalog celotne glasbene zbirke je pripravil Alessandro Arbo, I fondi musicali dell'Archivio storico provinciale di Gorizia.

2 Termin uvertura za instrumentalno delo, ki uvaja opero, se je uveljavil šele s koncem 18. stoletja. 
generacije $^{3}$ je ta kompozicija naslovljena kot Concerto a quatro del signor don Antonio Vivaldi. Tekom 18. stoletja žanri še niso bili striktno (do)ločeni in tudi termini za njihovo označbo so se uporabljali nedosledno. Iz tega sledi, da je potrebno pri raziskovanju simfonije 18. stoletja upoštevati vse njene manifestacije in vzeti pod drobnogled skoraj vsa trostavčna instrumentalna dela za številnejšo godalno zasedbo; da je tako, kaže tudi pet zbirk skladb za godalni kvartet (dve violini, viola in bas) oz. trio (dve violini in bas), ki jih hrani goriški arhiv.

$\mathrm{V}$ omenjenih petih zbirkah se prepletajo dela od prve polovice 18. stoletja naprej, označena s termini kvartet, trio, sinfonia, divertimento in sonata. Kot je bilo rečeno, te označbe še ne razkrivajo, za katero žanrsko zvrst pravzaprav gre, mestoma pa je žanrsko zvrst tudi težko označiti. Poleg tega se ob študiju zbirke pojavljajo težka vprašanja v zvezi $\mathrm{z}$ avtorstvom; precej del nima navedenega avtorja ali pa navedbe ni mogoče potrditi. Zbirke so skupek muzikalij različnih prepisovalcev, ki so bile v zvezke vezane šele naknadno.

Vsaj ena od omenjenih zbirk kaže, da dela niso bila naključno zbrana. Skladatelji skladb so bili namreč sodobniki in vsi so delovali v nemškem prostoru. Zbirka vsebuje devet kompozicij Johanna Stamitza (1717-1757), naslovljenih kot Sonatte. Izmed teh lahko samo za eno potrdimo, da je Stamitzova Simfonija v B-duru (Wolf B-4). Simfonija je iz skladateljevega zgodnjega obdobja in je najverjetneje nastala med leti 1841 in 1848 . Simfonija ima tri stavke, ki sledijo shemi hitro-počasi-hitro, in namenjena je zasedbi dveh violin, viole in basa (ki je bil lahko podvojen z violončelom, fagotom in čembalom). Ostale Stamitzu pripisane skladbe zbirke se od te simfonije ne ločujejo bistveno; sledijo isti stavčni shemi in zasnovane so v sorodnem kompozicijskem stavku. Stamitzeve zrelejše simfonije so imele naprednejše lastnosti, ki so zaznamovale tedanjo simfonično ustvarjalnost in ustvarjalnost nadaljnje generacije.

V isti zbirki je Simfonija v Es-duru (Münster 11) Carla Giuseppe Toeschija (1731-1788), Stamitzevega učenca. Je tipična predstavnica Toeschijevih simfonij: ima tri stavke; prvi je v sonatni obliki in uvaja ga štiritaktni akordski uvod. Godalno zasedbo je Toeschi razširil $\mathrm{z}$ dvema oboama in dvema rogovoma (konvencionalna zasedba za simfonije od štiridesetih let dalje). V zbirki sta še Simfonija v F-duru Johanna Gabriela Seyffartha (1711-1796) in Simfonija v B-duru (Warburton C Inc 1) Johana Christiana Bacha (1735-1782). Kot Toeschijeva simfonija tudi slednja poleg godal predvideva še dve oboi in dva rogova. Simfonija v B-duru sodi med Bachova zgodnja dala, saj je nastala pred njegovo selitvijo v London leta 1762.

V drugi zbirki je zbranih 62 del. Med njimi je Simfonija $v$ g-molu Ignaza Jacoba Holzbauerja (1711-1783), skladatelja prve generacije mannheimske šole. V zbirki je precej anonimnih del. Nekatera izkazujejo konvencionalno stavčno shemo zgodnjih simfonij. Podobno velja za 26 anonimnih del tretje zbirke. V slednji naj bi bile tudi štiri simfonije Georga Christopha Wagenseila (1715-1777), vendar mu zagotovo lahko pripišemo le tri. ${ }^{4}$ Wagenseil je bil osrednja figura v razvoju zgodnje simfonije na Dunaju. V zbirki zasledimo tudi delo Sinfonia Baldasasara Galuppija (1706-1785), ki je pravzaprav uvertura

3 Taruskin, The Oxford History of Western Music, zv. 2, The Seventeenth and Eighteenth Centuries, 497.

4 Gre za Simfonijo v Es-duru (Scholz Mischeltisch, 390), Simfonijo v D-duru (Scholz Mischeltisch, 423) in Simfonijo v B-duru (Scholz Micheltzsch, 439). 
k operi Vologeso. Galuppi je bil vpliven in priljubljen skladatelj opere serie. Posvečal se je tudi cerkveni glasbi in solističnim skladbam za instrumente s tipkami, samostojnih orkestralnih del pa je napisal zelo malo.

Težave pri ugotavljanju avtorstva se pojavijo še pri zadnjih dveh zbirkah. Ena od teh obsega žal le part za drugo violino. Zadnja, ki je spet žanrsko raznolika, vsebuje tudi kompozicijo z naslovom Apertura a quattro (uvertura), ki je najverjetneje delo grofa Giorgia Giulinija (1716-1780), učenca Giovannija Battista Sammartinija. Giulini je bil popularen diletantski skladatelj simfonij..$^{5}$ Arhiv sicer ne hrani nobene Sammartinijeve simfonije, hrani pa Simfonijo v Es-duru, ki mu je bila zmotno pripisana. Najverjetneje gre za delo Antonija Brioschija (ok. 1725-ok. 1750), Sammartinijevega sodobnika iz severne Italije. Brioschijev stil je zelo podoben Sammartinijevemu in zato so mnoga dela zmotno veljala za njegova. ${ }^{6}$

Med ohranjenimi deli izstopa Sinfonia per chiesa neznanega avtorja. Teoretiki 18. stoletja so izpostavljali posebno zvrst simfonije, imenovano sinfonia da chiesa (cerkvena simfonija), ki naj bi bila zastavljena skromneje kot koncertna in komorna simfonija; omejena naj bi bila na en stavek ali največ dva in po možnosti naj bi se držala oblikovne sheme »dobro izdelane fuge «. ${ }^{7}$ Simfonije, ki bi ustrezale naštetim kriterijem, so zelo redke in značilne so samo za italijanski prostor. Navedene lastnosti vidimo tudi v omenjeni skladbi: simfonija je skromneje instrumentirana (dve violini, violone, flavta in orgle); tekom skladbe si instrumenti imitacijsko izmenjujejo temo; skladba žal ni v celoti ohranjena in tako njene enostavčnosti ni mogoče potrditi.

Ostale simfonije, hranjene v arhivu, datirajo v konec 18. stoletja in so primeri zrelega štiristavčnega ciklusa $\mathrm{z}$ bogatejšo instrumentacijo in pestrejšimi oblikovnimi shemami stavkov. Presenetljivo je, da sta v arhivu prisotni samo dve simfoniji J. Haydna. Njegove simfonije so bile namreč ob koncu 18. stoletja nepogrešljiv del glasbene kulture. Arhiv hrani Simfonijo št. 73 v D-duru, »Lov«, in Koncertanto simfonijo št. 105 v B-duru. Haydn je v zadnji stavek Simfonije št. 73 vpletel stilizirane lovske klice, po čemer je simfonija dobila vzdevek »Lovska«. Karakteristične simfonije so postale priljubljene v drugi polovici 18. stoletja in njihova tipična predstavnica je tudi priljubljena Simfonija $v$ G-duru, La festa della pace Franza Antona Hoffmeisterja (1754-1812). Poleg lova in vojaških tem so skladatelji skušali v simfonije vplesti tudi narodne karakteristike. Hoffmeister je v četrtem stavku tako vpeljal značilnosti turške glasbe. ${ }^{8}$

Simfonije Adalberta Gyrowetza (1763-1850) so bile zelo razširjene po Habsburških deželah, pogoste so bile tudi na koncertnih sporedih v Parizu in Londonu. ${ }^{9}$ Arhiv hrani pet njegovih simfonij..$^{10}$ John A. Rice meni, da so bile njegove simfonije »lahke za igranje in poslušanje« in da je to tudi razlog za njihovo popularnost, saj niso zahtevale tehničnega

5 Churgin, »Sammartini, Giovanni Battista«, v: Grove Music Online.

6 Jenkins in Churgin, Thematic Catalogue of the Works of Giovanni Battista Sammartini, 231.

7 Zaslaw, »Mozart, Haydn and the Sinfonia da Chiesa«, 96-100.

8 Simfonija je bila poklon koncu vojne, ki je potekala med Avstrijo in Turčijo od 1787 do 1791.

9 Jones, The symphony in Beethoven's Vienna, 5.

${ }^{10}$ Simfonije v F-duru (Rice F1), v B-duru (Rice B|b1), v C-duru, op. 8 (Rice C2), v C-duru, op. 13 (Rice C3) in v Es-duru, op. 18 (Rice Es5). 
in mentalnega napora. ${ }^{11}$ Poleg Gyrowetza je bil goriškim poslušalcem pri srcu tudi Ignaz Pleyel (1757-1831), saj je v arhivu kar šest njegovih simfonij. ${ }^{12}$ Pleyelova dela so bila izjemno popularna; ohranjeno je namreč na tisoče rokopisov in tiskanih izvodov njegovih del. ${ }^{13}$ Prav zaradi izredne priljubljenosti je bil ponekod bolj poznan kot Haydn in Mozart, kar potrjuje tudi goriški arhiv. ${ }^{14}$ Pleyelov čar se najverjetneje skriva v njegovem liričnem pristopu; namesto izpeljav in obdelav tematskega gradiva je namreč raje uvajal nove teme..$^{15}$

Arhiv hrani tudi Simfonijo v D-duru (op. 12) in Simfonijo v G-duru (op. 22) Otta Carla Erdmanna von Kospotha (1753-1817), najslavnejšega in najbolj inovativnega diletanta, za čigar glasbo velja, da je prijetna in lahkotna. ${ }^{16}$ Med danes pozabljenimi skladatelji je tudi Franz Krommer (1759-1831), plodovit in priznan skladatelj svojega časa, prisoten v goriškem arhivu s Simfonijo v F-duru, op. 12. Ohranjeni sta še dve anonimni orkestralni skladbi iz druge polovice 18. stoletja. Prva izmed njiju je koncertantna simfonija s solističnimi instrumenti flavto, fagotom in violino (signatura Mns. 128), druga pa tipična trostavčna simfonija (Mns. 133).

Značilnosti simfonij kažejo, da so bile goriškim poslušalcem ljubše take simfonije, ki niti za izvajanje niti za razumevane niso bile prezahtevne in so se nagibale k izraziti spevnosti. Morda sta ravno zato ohranjeni le dve Haydnovi simfoniji in nobena Mozartova. Za simfonični repertoar Habsburške monarhije je bilo značilno, da je bil skoraj izključno naklonjen lokalni ustvarjalnosti, kar potrjuje tudi zbirka v goriškem arhivu. Ob pretežno avstrijskih (oz. v avstrijskem prostoru delujočih) skladateljih je tako le malo takih, ki potrjujejo vpliv italijanskega okolja. Med temi je beneški glasbenik Angelo Baldan (1753-1803). Arhiv hrani tiskano zbirko njegovo šestih simfonij iz leta $1785 .{ }^{17}$ Te simfonije so modelirane po značilnostih zgodnjih simfonij. Vse so namreč trostavčne in pisane za instrumentalno zasedbo, ki je bila značilna za sredino stoletja (2 vl, vla, bas, 2 ob in 2 cor); instrumentirane so tako, da pihala in trobila le podvajajo godala in nimajo nobene solistične vloge, v nekaterih počasnih stavkih pa so celo izpuščena. Glasbeni stavek je prav tako zazrt nazaj; prisotna je gradnja z dvotaktji, ki se sekvenčno ponavljajo in ne stremijo h gradnji tem.

Med ohranjenimi deli je potrebno izpostaviti še skladbo Sinfonia d'un Aria della Farsa Zelinda e Lindoro Venceslava Wratnyja (1748-1810). Češki skladatelj se prvič omenja leta 1783 , ko naj bi že deloval kot kapelnik v Gorici. ${ }^{18} \mathrm{Na}$ Goriškem je bil očitno deležen mecenske podpore barona Petra Antona Codellija, kateremu je skladbo tudi posvetil. Gre za kratko enostavčno delo, katerega značaj spominja na rossinijevski tip uverture. ${ }^{19}$

V zbirki so tudi uverture, nastale v osemdesetih in devetdesetih letih 18. stoletja, ki so krožile kot samostojne skladbe. Uvertura je bila, tako kot simfonija, podvržena stalnemu

${ }^{11}$ Rice, "Adalbert Gyrowetz. Introduction «, xxv.

${ }^{12}$ Simfonije v F-duru (Benton 140A), v D-duru (Benton 145), v D-duru (Benton 133), v C-duru (Benton 128), v d-molu (Benton 147) in v B-duru (Benton 135).

${ }^{13}$ Benton, »Ignace Joseph Pleyel«, v: Grove Music Online.

${ }^{14}$ Badley, »Ignaz Joseph Pleyel«, 542.

${ }_{15}$ Nav. delo, 547.

${ }^{16}$ Unverricht, »Kospoth«, v: Grove Music Online.

${ }^{17}$ Simonetti, »Baldan, Angelo«, v: Dizionario Biografico degli Italiani (splet).

${ }^{18}$ Höfler, Tokovi glasbene kulture na Slovenskem, 133.

${ }^{19}$ Barbo, »Simfonični začetki na Slovenskem in pastoralni izraz«, 142-143. 
razvoju, in v osemdesetih letih se je njena oblika standardizirala. Žanrska meja, ki je bila med uverturo in simfonijo prej zabrisana, je postajala vedno bolj očitna (terminska raba pa je ostala nedosledna še v 19. stoletje). Uverture, hranjene v arhivu, so pripadale operam, ki so bile zelo uspešne po celotni Evropi, in delom, ki izven Italije niso dosegla večje prepoznavnosti. Goriška zbirka tako hrani uverturo k operi La maga Circe Pasquala Anfossija (1727-1797). Gre za enostavčno delo v sonatni obliki. La maga Circe je bila premierno izvedena v karnevalu leta 1788, in sicer v gledališču Teatro Valle v Rimu, večje popularnosti pa izven meja Italije ni dosegla. ${ }^{20}$ Simon Mayr (1763-1845) je igral ključno vlogo v razvoju opere serie konec 18 . stoletja in začetek 19. stoletja. ${ }^{21}$ Njegova operna dela so bila zelo popularna in kmalu je veljal za enega najboljših italijanskih skladateljev. ${ }^{22}$ Prav opera Gli Sciti pa naj ne bi sodila med njegove uspešnejše opere. ${ }^{23}$

Obe deli Vicenta Martín y Solerja (1754-1806), izključno opernega komponista, že v naslovu nakazujeta, da gre tudi v tem primeru za uverturi k operam: Sinfonia Dal Sig.r Vicenzo Martini Nella Cosa Rara in Sinfonia Del Sig.r Vincenz Martini Nella Capricciosa Corretta. Martín y Soler je izjemen uspeh doživel prav s komično opera Una cosa rara (1786), ki je nastala za dunajski dvor. Občinstvo naj bi prevzele njegove »ljubke in sladke melodije «. ${ }^{24}$ Gre za zelo kratko enostavčno delo, v katerem so združene prvine sonatne oblike in rondoja. Komična opera La scuola dei maritati oz. La capricciosa corretta je bila prvič izvedena leta 1795 v King's Theater v Londonu in bila je ena najbolj priljubljenih oper tiste sezone..$^{25}$ Instrumentacija obeh uvertur je v samostojni različici manj razkošna, saj parta klarinetov (v primeru uverture k Una cosa rara parta flavt) tu prevzameta oboi. Izjemno priljubljena je bila tudi opera Démophon Johanna Christopha Vogla, ki je bila izvedena leta 1789 v pariški operi. Uvertura je bila popularna še v prvih dveh desetletjih 19. stoletja. ${ }^{26}$ Zbirka hrani tudi uverturi k operama Don Giovanni in Cosi fan tutte, edini orkestralni skladbi W. A. Mozarta v arhivu.

Med uverturami izstopa uvertura Martina Nisleja (1780-1861). Nisle ni napisal nobenega dramatičnega dela; uvertura je bila tako po vsej verjetnosti komponirana kot samostojna koncertna skladba. V prvem desetletju 19. stoletja so že nastajale prve koncertne uverture, samostojna enostavčna dela, pisana za slovesna praznovanja, kot so bila npr. otvoritev gledališča ali nacionalna praznovanja. ${ }^{27}$

Iz pripisov na notnem gradivu je razvidno, da je bil posvetni del zbirke last več goriških plemiških družin. Za simfonično glasbo pa lahko sklepamo, da sta bila njena poglavitna gojitelja baron Peter Anton Codelli in Carlo della Torre. Ohranjene muzikalije potrjujejo, da so se dela tudi izvajala. Na mnogih namreč najdemo oznake in popravke. Tudi dodatni prepisi partov za godala to potrjujejo. Število dodatnih partov razkriva, katera izvajalska zasedba je bila na voljo. Tako je orkester, ko je igral v največji zasedbi,

\footnotetext{
${ }^{20}$ Maierhofer, »Transformations on Stage Only«, 85.

${ }^{21}$ Balthazar, »Mayr, (Johann) Simon«, v: Grove Music Online.

22 Nav. delo.

${ }^{23}$ Rice, »Gli Sciti: Voltaire's Play, Beretti's Ballet, Mayr's Opera« (splet).

${ }^{24}$ Link, »Cosa rara, Una«, v: Grove Music Online.

${ }^{25}$ Link, »Martín y Soler«, v: Grove Music Online.

${ }^{26}$ Jacobshagen, »Vogel, Johann Christoph«, v: Grove Music Online.

${ }^{27}$ Temperley, »Overture«, v: Grove Music Online.
} 
imel vsaj pet prvih in pet drugih violin; skupaj je obsegal vsaj 25 glasbenikov in ga lahko primerjamo z orkestri po Habsburški monarhiji drugod. Zasedba, ki je igrala Beethovnovo Eroiko v Gorici, je bila namreč po številnosti skoraj identična zasedbi na vajah pred prvo izvedbo te simfonije. ${ }^{28}$

Klasicistični simfonični repertoar Goričanov se tako zaključuje s prvo in tretjo simfonijo Ludwiga van Beethovna ter Simfonijo v D-duru, op. 8, in Simfonijo v G-duru, op. 9, Beethovnovega sodobnika Johanna Baptista Schiedermayra (1779-1839). Najverjetneje so bila ta dela med zadnjimi simfoničnimi deli poznega klasicizma, ki jih je goriška publika še spoznala. V arhivu namreč ne najdemo kasnejših simfoničnih del, pa tudi preostali viri navajajo le izvedbe Mozartovih uvertur in izvedbo nedoločene Beethovnove uverture v dvajsetih letih 19. stoletja. ${ }^{29} \mathrm{~S}$ tega vidika je bil klasicizem na Goriškem res le kratka epizoda. ${ }^{30} \mathrm{~K}$ temu je pripomoglo več razlogov: Ilirske province so Goriško ekonomsko opustošile in prekinile tesen stik s habsburško prestolnico; tudi okus publike je postajal vedno bolj naklonjen italijanski operi in njej sorodni glasbi.

\section{Uporabljena literatura}

Arbo, Alessandro. »Dusík, Wrattni e la ricezione del Klassik musicale centroeuropeo a Gorizia nei primi decenni dell'Ottocento«. V: Itinerari del Classicismo musicale: Trieste e la Mitteleuropa, ur. Ivano Cavallini, 39-54. Lucca: Libreria Musicale Italiana, 1992.

___ . I fondi musicali dell'Archivio storico provinciale di Gorizia. Gorica: Provincia, 1994.

-_- Musicisti di frontiera: Le attività musicali a Gorizia dal Medioevo al Novecento. Gorica: Edizioni della Laguna, 1998.

Badley, Allan. »Ignaz Joseph Pleyel«. V: The Eighteenth-Century Symphony, ur. Marry Sue Morrow in Bathia Cherugin. The Symphonic Repertoire, zv. 1, 542-548. Indiana: Indiana University Press, 2012.

Balthazar, Scott L. »Mayr, (Johann) Simon«. V: Grove Music Online (splet).

Barbo, Matjaž. »Simfonični začetki na Slovenskem in pastoralni izraz«. V: Imaginacija narave v umetnosti ali 'Glasba naj posnema naravo v njenem načinu delovanja', ur. Primož Kuret, 142-150. Ljubljana: Festival, 2013.

Benton, Rita. »Ignace Joseph Pleyel«. V: Grove Music Online (splet).

Churgin, Bathia. »Sammartini, Giovanni Battista«. V: Grove Music Online (splet).

${ }^{28}$ Orkester Princa Lobkowitza na vajah pred koncertom Beethovnove 3. simfonije: $2 \mathrm{fl}, 2 \mathrm{ob}, 2 \mathrm{cl}$, 2 fag, 3 cor, 2 tr, 7 vl, 2 vla, 2 vlc, 2 bas, timp. Skupaj: 27. Število glasbenikov, ki jih nakazujejo parti Beethovnove 3. simfonije, hranjeni v Gorici: 2 fl, 2 ob, 2 fag, 3 cor, 2 tr, najmanj 8 vl, 2 vla (verjetno), timp, bas in vlc (najmanj 3). Skupaj: 25. Gl. Volek in Macek, »Beethoven's Rehearsals at the Lobkowitz's, «75-80.

${ }^{29}$ Arbo, Musicisti di frontiera, 74.

${ }^{30}$ Arbo, »Dusík, Wrattni e la ricezione del Klassik musicale centroeuropeo a Gorizia nei primi decenni dell'Ottocento«, 50. 
Höfler, Janez. Tokovi glasbene kulture na Slovenskem od začetkov do 19. stoletja. Ljubljana: Mladinska knjiga, 1970.

Jacobshagen, Arnold. »Vogel, Johann Christoph«. V: Grove Music Online (splet).

Jenkins, Newell, in Bathia Churgin. Thematic Catalogue of the Works of Giovanni Battista

Sammartini: Orchestral and Vocal Music. Cambridge, Mass.: Harvard University Press, 1976.

Jones, David Wyn. The symphony in Beethoven's Vienna. Cambridge: Cambridge University Press, 2006.

Link, Dorothea. »Cosa rara, Una«. V: Grove Music Online (splet). . »Martín y Soler, Vicente«. V: Grove Music Online (splet).

Maierhofer, Waltraud. »Transformations on Stage Only: Anfossi's Circe in Weimar«. V: Operatic Migrations: Transforming Works and Crossing Boundaries, ur. Roberta Montemorra Marvin in Downing A. Thomas, 85-98. Aldershot: Ashgate publishing, 2006.

Rice, John A. "Adalbert Gyrowetz. Introduction«. V: Adalbert Gyrowetz 1763-1850, Four Symphonies, Jan Ladislav Dussek 1760-1812, One Symphonie Concertante, ur. John A. Rice in H. Allen Craw. The Symphony 1720-1840, ur. Barry S. Brook, serija B, zv. 11, xiii-xxxi. New York: Garland, 1983.

____ „ „Gli Sciti: Voltaire's Play, Beretti's Ballet, Mayr's Opera« (splet; referat na simpoziju Simon Mayr: Der Bayerische Komponist im europäischen Kontext, Ingolstadt, 21.-24. september 2006).

Simonetti, Silvana. »Baldan, Angelo«. V: Dizionario Biografico degli Italiani, zv. 5 (splet). Taruskin, Richard. The Oxford History of Western Music. Zv. 2, The Seventeenth and

Eighteenth Centuries. New York: Oxford University Press, 2005.

Temperley, Nicholas. »Overture«. V: Grove Music Online (splet).

Unverricht, Hubert. »Kospoth, Otto Carl Erdmann, Freiherr von«. V: Grove Music Online (splet).

Volek, Tomislav, in Jaroslav Macek. »Beethoven's Rehearsals at the Lobkowitz's«. V: The Musical Times, 127, št. 1716 (1986): 75-80.

Zaslaw, Neal. »Mozart, Haydn and the Sinfonia da Chiesa«. The Journal of Musicology 1, št. 1 (1982): 95-124.

\section{THE SYMPHONIC REPERTOIRE IN THE GORIZIA REGION IN THE EIGHTEENTH AND EARLY NINETEENTH CENTURIES}

\section{Summary}

The Historical Archive in Gorizia holds a large collection of music from the eighteenth and early nineteenth centuries. It consists of church, chamber, solo and symphonic works. The secular works were previously owned by several aristocratic families that lived in the county of Gorizia (one of the crown lands of the Habsburg Empire), among which the most generous music patrons were the Attems, Coronini, della Torre and Codelli families. The 
collection includes symphonies of Georg Christoph Wagenseil, Johann Stamitz, and other Mannheim composers, as well as Italian composers such as Antonio Brioschi. These early symphonic examples are mostly scored for two violins, viola, and bass (which was doubled by violoncello, bassoon, and / or harpsichord in the performances). The symphonies have been placed into five bound volumes that consist of various genres from trio sonatas, overtures, and symphonies to quartets. Several works are anonymous, many lack genre indications, and for some of them only the second violin part has survived. Among the anonymous works there are also three- or four-part compositions in three (non-dance-like) movements (fast-slow-fast), which was the conventional form of early symphonies. There are also some overtures from the late eighteenth century taken from operas ranging from the most famous European examples (Johann Christoph Vogel's Démophon, Mozart's Così fan tutte and Don Giovanni, Vincente Martin y Soler's Una cosa rara) to operas popular solely in Italy. The symphonies from the late period of the century are works of Adalbert Gyrowetz, Ignaz Pleyel, Franz Krommer, Otto Carl Erdmann von Kospoth, Johann Baptist Schiedermayr and Ludwig van Beethoven (first and third symphonies). Interestingly, there are only two symphonies by Joseph Haydn and none by Mozart. These late symphonies were obtained mostly as printed editions. The early symphonies are examples of the most influential and prolific composers of various European regions. The musical taste of the local nobility seems to have been adapted to other parts of the Empire, in which music of native composers mostly prevailed. The Italian influence may be seen in some rare works by Italian composers (e.g., the printed collection of symphonies by Angelo Baldan). Numerous marks and corrections on the musical material confirm that these works were performed. The number of additional string parts for the symphonies from the end of the century indicates that the orchestra consisted of at least twenty-five musicians, which means that it was comparable to other aristocratic orchestras of the time. 